\title{
Perceived Interparental Conflict and Early Adolescents' Friendships: The Role of Attachment Security and Emotion Regulation
}

\author{
Beate Schwarz $\cdot$ Melanie Stutz $\cdot$ Thomas Ledermann
}

Received: 10 January 2012/Accepted: 22 April 2012/Published online: 9 May 2012

(C) Springer Science+Business Media, LLC 2012

\begin{abstract}
Although there is strong evidence for the effect of interparental conflict on adolescents' internalizing and externalizing problems, little is known about the effect on the quality of adolescents' relationships. The current study investigates the link between adolescents' friendships and interparental conflict as reported by both parents and adolescents. It considers early adolescents' emotion regulation ability and attachment security as mediators. The analysis is based on a longitudinal study with two waves separated by 12 months. The participants were 180 two-parent families and their adolescent children (50.5\% girls), the average age of the latter being 10.61 years $(\mathrm{SD}=0.41)$ at the outset (Time 1). Binomial logistic regression analysis revealed that perceived interparental conflict increased the risk of instability in friendship relationships across the 1 -year period. Structural equation modeling analysis indicated that the association between perceived interparental conflict and friendship quality was mediated by emotion regulation and attachment security. The discussion focuses on mechanisms whereby interparental conflict influences early adolescents' friendship relationships.
\end{abstract}

Keywords Interparental conflict - Early adolescents' friendships - Emotion regulation - Attachment security

B. Schwarz $(\bowtie)$

Department of Applied Psychology, Zurich University

of Applied Sciences (ZHAW), Minervastr. 30,

8032 Zurich, Switzerland

e-mail: beate.schwarz@zhaw.ch

M. Stutz · T. Ledermann

Department of Psychology, University of Basel,

Basel, Switzerland

\section{Introduction}

Deleterious effects of interparental conflict on internalizing and externalizing problems of children and adolescents have been well documented (see the meta-analysis by Buehler et al. 1997). Some authors, however, have pointed to the narrow perspective of these child outcomes (e.g., Kinsfogel and Grych 2004; Parke et al. 2001; Stocker and Youngblade 1999). These authors emphasized that the quality of parents' relationship and the way they negotiate conflict should have an impact on the socio-emotional development of the children. Further, the family is the primary context in which we learn about relationships (Lucas-Thompson and Clarke-Stewart 2007). Given the developmental significance of peer and friendship relationships in childhood and adolescence (Hartup 1996; Rubin et al. 2006a), there is a surprisingly small number of studies investigating the impact of interparental conflict on the quality of peer relationships and friendships, especially with respect to the age period of early adolescence, when the nature of peer and friendship relationships changes substantially (Hartup 1996; Rubin et al. 2006a). The aim of the current study is to examine the effects of perceived interparental conflict on the stability and quality of the relationship with the best friend.

Several studies have found indirect (mediated) effects of interparental conflict on children's and adolescents' development, such as children's appraisal of conflict (e.g., Buehler et al. 2007; Siffert and Schwarz 2011a), parenting (e.g., Erel and Burman 1995; Siffert et al. in press), emotion regulation (e.g., Buehler et al. 2007; Harold et al. 2004; Siffert and Schwarz 2011a), and attachment (e.g., Doyle and Markiewicz 2005; Steinberg et al. 2006). The latter two mediators are especially relevant for social relationships. For example, the work of Nancy Eisenberg 
and colleagues (e.g., Eisenberg et al. 2004) has indicated that emotion regulation is an important competence for positive social relationships. In addition, the emotional security hypothesis explicates how emotion regulation abilities are influenced by interparental conflict (Davies and Cummings 1994). Attachment theory is a seminal theoretical approach in developmental psychology that emphasizes that attachment quality is influenced by experiences in the family and has predictive value for aspects of relationships outside the family (Bowlby 1969). On the basis of those theoretical considerations, the current study focuses on the role of early adolescents' emotion regulation abilities and attachment security as intervening variables in the association between interparental conflict and adolescents' friendships. By including both emotion regulation and attachment, which can be considered as processes from the emotional and the familial domain, this study contributes to the ongoing debate on the interconnectedness of mediators of the effect of interparental conflict (Davies et al. 2002; O’Donnell et al. 2010; Stocker et al. 2003).

\section{Interparental Conflict and Adolescents' Friendships}

Interparental conflict has been shown to increase the risk for internalizing and externalizing problems (Buehler et al. 1997). However, observing how parents negotiate situations of conflict also may have an important impact on the expectations children have about their social relationships outside the family and on how they behave with others (Kinsfogel and Grych 2004; Lucas-Thompson and ClarkeStewart 2007; Parke et al. 2001; Stocker and Youngblade 1999). Although the developmental importance of adolescents' friendships has been acknowledged (Hartup 1996; Rubin et al. 2006a), only a few studies (all cross-sectional) have been conducted on the association between interparental conflict and friendship quality. Noack et al. (2001) found that adolescents from high-conflict intact families reported lower admiration from their best friend than sameaged peers from low-conflict intact families or divorced families. Maternal and older children's ratings of inadequate conflict resolutions but no other aspects of perceived interparental conflict (e.g., intensity) were associated with lower friendship quality (Kitzmann and Cohen 2003). A study on 8-years old boys showed that the number of friends and friendship quality were indirectly related to interparental conflict via family conflict resolution strategies (Lindsey et al. 2006). In addition, studies that referred to marital quality (rather than interparental conflict) and to children's peer relationships (rather than friendships) can hint at which associations can be expected. In childhood and early adolescence, high interparental conflict was associated with low popularity in peer groups (MacKinnonLewis and Lofquist 1996; Parke et al. 2001). Moreover, the quality of marital relationship was related to fourthgraders' friendship quality (Lucas-Thompson and ClarkeStewart 2007). Longitudinal studies on the impact of interparental conflict on friendship relationships are still missing. Research on the effects of interparental conflict on the stability of friendship relationships is also lacking. Nevertheless, on the basis of the aforementioned evidence, one can conclude that there is an effect of interparental conflict on early adolescents' friendship quality and stability.

\section{Emotion Regulation}

The emotional security hypothesis (Davies and Cummings 1994) explains the negative effects of interparental conflict on children's and adolescents' development. According to this seminal theoretical approach, ongoing, intensive interparental conflict leads to emotional insecurity in children, who may consequently exhibit higher emotional reactivity, attempts inadequately to regulate their exposure to parents' conflict, and develop insecure internal representations of the interparental relationship. In the long run, emotional insecurity can undermine children's ability to regulate negative emotions such as anger, sadness, and fear (Davies et al. 2002). Emotion regulation is defined as "the process of initiating, avoiding, inhibiting, maintaining or modulating the occurrence, form, intensity, or duration of internal feeling states, emotion-related physiological processes, emotion-related goals, and the behavioral concomitants of emotion" (Eisenberg et al. 2004, p. 278). Eisenberg et al. (2000) argued that emotion regulation is a social process and that the regulation strategies influence how others react. Additionally, children with high emotion regulation abilities behave adequately in a social context, while those who cannot modulate their emotions well often show unconstructive behavior. This suggests that emotion regulation ability is positively related to social competence and the quality of social relationships (Eisenberg et al. 2004). On the basis of these theoretical reflections, one may conclude that children's ability to regulate emotions is a mediator for the relationship between interparental conflict and adolescents' friendships.

However, no study so far has investigated the mediating role of emotion regulation in the link between interparental conflict and friendship quality or stability. Empirical evidence is available on the association between interparental conflict and emotion regulation on one hand and emotion regulation and relationships with same-aged peers on the other. Cross-sectional and longitudinal studies emphasized the association between interparental conflict and children's and adolescents' emotion regulation (Buehler et al. 2007; Harold et al. 2004; Kinsfogel and Grych 2004; Mann and Gilliom 2002; Schulz et al. 2005). Difficulties in 
regulating one's emotions, in turn, consistently have been shown to be related to lower social competence in childhood (Eisenberg et al. 2004; Kim and Cicchetti 2010). Recent studies also indicated a link between adaptive emotion regulation and peer acceptance in adolescence (Lopez et al. 2005; Perry-Parrish and Zeman 2009); however, no study has investigated the importance of emotion regulation abilities for friendships in the same period.

\section{Attachment Security}

According to attachment theory, children develop an internal working model of the self in relation to others and of relationships with others based on previous experiences with the caregivers (Bowlby 1969). In the context of high interparental conflict, support from parents and their sensitivity for the needs of their children might be constrained. Additionally, the negative affect in the parental relationships can spill over into the relationship between parent and child (Erel and Burman 1995). This spillover can result in an insecure representation of social relationship in the internal working model (Bowlby 1969). The internal working model influences the child's expectations of the nature of relationships in general and their behavior in specific social interactions (e.g., with friends); thus, the specific internal working model of a child or an adolescent can influence the quality of friendships.

Some studies on early adolescence revealed that interparental conflict was related to lower attachment security in the relationship with parents (Davies et al. 2002; Doyle and Markiewicz 2005; Steinberg et al. 2006). A meta-analysis provided support for the association between attachment with the mother and friendship quality in both childhood and early adolescence (Schneider et al. 2001). This is also supported in a more recent study. Best-friend dyads in middle adolescence in which both friends were securely attached showed, on a trend level, higher friendship quality compared to dyads with at least one insecure attached friend (Weimer et al. 2004). For early adolescence, a medium size correlation between maternal and paternal support (as indicators of attachment) and perceived friendship quality was reported (Rubin et al. 2004). Studies have investigated the mediating role of attachment security for the association between indicators of parents' relationship and adolescents' social relationships, but not for the association between interparental conflict and adolescents' friendships. Using a cross-sectional design, Steinberg et al. (2006) showed that attachment security partially mediated the relationship between interparental conflict and romantic relationships. The studies of LucasThompson and Clarke-Stewart (2007) and Markiewicz et al. (2001) indicated that attachment security with parents mediated the association between marital quality and friendship quality. No study so far has investigated the meditational role of attachment for the association between interparental conflict and friendship quality over time.

\section{The Association Between Emotion Regulation and Attachment Security}

The concept of insecure representations of interparental relationships in the emotional security hypothesis shows some congruence with the construct of internal representation of the parent-child relationship as secure or insecure in attachment theory (Bowlby 1969). Nevertheless, Davies et al. (2002) pointed out that security in the context of the interparental relationship differs from security in the parent-child relationship. In a study with early adolescents, the authors showed that emotional security and parentchild attachment are distinct constructs (Davies et al. 2002). Thus, adolescents' internal representations of the relationship with parents and emotion regulation should be treated as separate but interconnected mediators. Some authors argue that emotion regulation is a mediator for the association between attachment security and friendship relationships (Contreras and Kerns 2000); empirical results corroborate this argument. Mother-child attachment security was related to peer competence, directly and also indirectly via emotion regulation (Contreras et al. 2000). So, the current study also will investigate the indirect path of attachment to friendship quality through emotion regulation.

\section{Friendship Relationships in Early Adolescence}

We investigated the impact of interparental conflict on friendship relationships in early adolescents. This is a very specific period of human development as it is characterized by the onset of puberty, which is usually defined as the beginning of adolescence. Due to the fundamental changes in physical, cognitive, and emotional development, social relationships start to change (Collins and Steinberg 2006). The individuation from parents begins and the relationships with friends change. For example, time spent with friend's increases, at least for girls (Larson and Richards 1991). While some studies have found evidence for an improvement of the friendship quality from late childhood to early adolescence (Furman and Buhrmester 1992) and from early to middle adolescence (Selfhout et al. 2008), a study by Fanti et al. (2009) found no such evidence. Furthermore, the rank-order stability of friendship quality in early adolescence has turned out to be high (Fanti et al. 2009), as is the case for stability of specific friendship relationships (Berndt and Hoyle 1985; Rubin et al. 2006b). The evidence has so far suggested that early adolescence can be considered a period of significant mean changes in the 
characteristics of the friendship quality but of relatively high stability in friendship quality and in the relationships themselves.

With respect to the developmental significance of friendships, Hartup (1996) concluded that having a good quality relationship with a friend supports academic and emotional adjustment across school transitions. Moreover, recent studies showed that high friendship quality buffers against the negative effects of family stress (such as arises from inadequate parenting) on adolescents' adjustment (Lansford et al. 2003). However, Hartup (1996) pointed out that still more research on friendship quality is needed, especially in the context of personal and family factors (cf. Rubin et al. 2006b). The current study adds to the littlestudied field of friendship relationships in the context of family experiences by investigating interparental conflict.

\section{Goals of the Current Study and Hypotheses}

The current study pursued two objectives. The first one was to investigate the association between perceived interparental conflict and the stability of relationships with friends. On the basis of evidence for the deleterious effect of interparental conflict on a diversity of developmental areas, we hypothesized that interparental conflict undermines the stability of friendships. The second objective was to ascertain and characterize the mechanism whereby perceived interpersonal conflict affects friendship quality through emotion regulation and attachment security; by integrating both emotional and familial processes, the current study provides insight into the interconnected nature of these mediators (Davies et al. 2002; O'Donnell et al. 2010; Stocker et al. 2003).

With respect to the first objective, we hypothesized that interparental conflict undermines the stability of friendship relationships (H1). In a more exploratory sense, we tested whether emotion regulation and attachment security are mediators of this association. With respect to the second objective, in accordance with the emotional security hypothesis, we expected that the link between perceived interparental conflict and the quality of adolescents' friendships is mediates by adolescents' emotion regulation (H2). More specifically, we expected a negative association between perceived interparental conflict and adaptive emotion regulation and a positive association between adaptive emotion regulation and friendship quality. In line with attachment theory, attachment security was hypothesized to mediate the link between perceived interparental conflict and friendship quality across time (H3). Again, we expected a negative link between perceived interparental conflict and attachment security and a positive link between attachment security and friendship quality. Based on the results of Contreras et al. (2000), we hypothesized that emotion regulation mediates the link between attachment security and friendship quality (H4) with a positive association between attachment security and adaptive emotion regulation. Using a longitudinal design, the current study adds to the existing and not yet abundant literature in this domain by investigating the effects of interparental conflict on early adolescents' friendship quality.

\section{Method}

Procedure

The analyses were based on the first (2008) and second assessment (2009) of a longitudinal study in the Germanspeaking part of Switzerland. The majority of the sample $(77.3 \%)$ was recruited by us in primary schools in the city of Basel (Switzerland) and its surroundings. Further families (22.7\% of the sample) were recruited through resident registration offices. The response rate was of $17 \%$ on average, a figure comparable to that of other multigenerational studies (e.g., Davila et al. 2003). Families were contacted for the first interview after returning a signed letter of consent. Trained interviewers conducted a $2 \mathrm{~h}$ long standardized interview at the family's home, with the mother and the adolescent in separate rooms. For twoparent families, a questionnaire was left behind for the husband or the male partner to be completed and sent back by mail. Each family received 30 Swiss Francs (equivalent to 29 US Dollars) for its participation.

\section{Participants}

In the current two-wave study, 246 fourth graders and their mothers participated at Time 1 and 228 mother-child dyads participated again 12 months later at Time 2 (attrition rate: $7.3 \%$ ). Participation in the second wave was elicited by sending families a summary of interesting results between the assessment periods. We found no differences in sociodemographic characteristics between one-time and repeat participants. 48 of the families were excluded from the study because interparental conflict was not obtained from one-parent households. Therefore, the analyses are based on 180 early adolescents living in two-parent households, of whom $92.8 \%(n=167)$ lived together with their biological mother and father, $5.6 \%(n=10)$ with their biological mother and their stepfather, and $1.7 \%(n=3)$ with adoptive or foster parents. 130 fathers participated.

The sample included 89 boys and 91 girls (age: $\mathrm{M}=10.61 ; \mathrm{SD}=0.41$ at Time 1$)$. At Time 1 , a majority of parents was married (94\%). On average, the families 
had 2.46 children $(\mathrm{SD}=1.05$; range $=1-7$ children $)$. Most of the parents were Swiss $(82.2 \%$ mothers and $81.7 \%$ fathers) and the average age was 42.55 years $(\mathrm{SD}=4.87)$ for the mothers and 45.15 years $(\mathrm{SD}=5.31)$ for the fathers. With respect to education, $9.4 \%$ of mothers and $6.1 \%$ of fathers had only completed the 9 years of compulsory education, a majority had finished formal job training ( $66.7 \%$ of the mothers and $52.0 \%$ of the fathers), and $23.9 \%$ of mothers and $41.9 \%$ of the fathers had attained a university or college degree. Demographically, the sample was biased toward well-educated Swiss families (Federal Statistical Office 2011).

\section{Measures}

Scales that were not available in German were translated by two members of the research team into German independently using a procedure suggested by Van de Vijver and Leung (1997). The reliability and validity of the German versions were tested in a pilot study of 50 10-year-old children. The indicators presented below are all composite scores of the items' mean.

\section{Perception of Interparental Conflict}

Following the notion of Grych et al. (1992) that the child's perspective on interparental conflict is important, we reffered to the adolescents' perception of interparental conflict. At Time 1, adolescents completed three subscales of the Children's Perception of the Interparental Conflict Scale (CPIC; Grych et al. 1992; validated German adaptation by Gödde and Walper 2001). For tapping the perception of frequency of interparental conflicts, three items were used (e.g., "My parents often argue."; $\alpha=.72$ ). Two items assessed the intensity of the conflict (e.g., "Even after my parents stop arguing, they stay mad at each other."; $\alpha=.61)$. The perception of parents' conflict resolution was measured with three items (e.g., "My parents find a solution."; $\alpha=.74)$. Adolescents rated the items from 1 (never) to 5 (very often).

\section{Parents' Negative Conflict Resolution}

In addition to the adolescents' reports, we included parents' perception on interparental conflict in the analysis. At Time 1, mothers and fathers completed the subscales for conflict engagement and withdrawal of the Conflict Resolution Styles Inventory (CRSI; Kurdek 1994; German adaptation by Gödde and Walper 2000). They indicated how frequently $(1=$ never to $5=$ always $)$ they use each of the styles when having an argument or disagreement with their partner. In a second part, they rated the same items also for their partner's behavior. Both subscales had a high internal consistency: conflict engagement (4 items; e.g., "Letting myself go, and saying things I do not really mean."; Cronbach's $\alpha$ ranged from .81 to .87) and withdrawal (4 items; e.g., "She/He doesn't listen to me anymore."; $\alpha$ ranged from .83 to .87$)$. The self-reports and partner reports of each conflict resolution style were averaged into a single score for each item (mother's conflict engagement, father's conflict engagement, mother's withdrawal, and father's withdrawal). This procedure was justified by the congruency between self-report on a specific conflict resolution style, and the respective partner report ( $r$ s ranged from .44 to .57; see Siffert and Schwarz 2011b).

\section{Adaptive Emotion Regulation}

At Time 2, the adolescents completed the FEEL-KJ, a questionnaire in German assessing children's and adolescents' emotion regulation (Grob and Smolenski 2005). In the original questionnaire, the children answered to parallel lists of items that referred to the regulation of anger, sadness, and happiness. In our multi-thematic study, we decided to focus on the reaction to anger because anger is an often investigated emotion. The adolescents responded to 14 items concerning seven adaptive strategies for coping with anger: problem orientation, distraction, mood enhancement, acceptance, oblivion, cognitive problem solving, and revaluation (e.g., "When I am angry, I make the best of the situation."; $\alpha=.91$ for all 14 items). Responses were indicated using a 5-point scale ranging from 1 (almost never) to 5 (almost always).

\section{Attachment Security}

To measure the adolescents' relationship with their mothers at Time 2, the adolescents rated 15 items of the Security Scale (Kerns et al. 2001). The item-format follows Harter's template (1985) "Some kids ... other kids ..." (Example item: "Some kids find it easy to trust their mom BUT Other kids are not sure if they can trust their mom."). The adolescents first chose the child who was most like them, and then rated on a 2-point-scale whether it was really true or sort of true, thereby producing answers on a 4-point-scale in which higher scores indicate a more secure attachment. Based on an exploratory factor analysis with AMOS (Arbuckle 2007), the original scale was reduced stepwise to an 8 -item-scale $(\alpha=.80)$. The exclusion criterion was a factor loading under $r=.40$. Given the length of the attachment questionnaire, we could not present the item battery for the relationship with the father within this multithematic study; so, no reports on attachment to fathers were available. 


\section{Friendship Characteristics}

At Time 1, the adolescents were asked for the name of their best same-sex friend. A year later, the interviewers verified whether they were still best friends. ("Last year you told us you were best friends with ... Are you still friends? And if yes, are you still best friends?"). A majority $(n=107)$ still considered the same person as his or her best friend, a few were no longer friends at all $(n=16)$, and others were still friends but no longer best friends $(n=55 ; 2$ missing values). As the latter two groups were small, a dichotomous variable of friendship instability (1: still best friends; 2 : no longer best friends) was created.

Ultimately, the early adolescents answered questions concerning friendship quality at Time 1 and 2 with respect to the actual best same-sex friend at the respective time point. For the current study, the friendship qualities scale of Bukowski et al. (1994) was translated into German. The data for friendship quality were gathered at Time 1 and 2 . We used four subscales: companionship, support, closeness, and security. For measuring companionship, four items were used (e.g., "My friend and I spend all our free time together."; $\alpha=.67$ at Time 1 and $\alpha=.60$ at Time 2 ). The indicator support consisted of five items (e.g., "My friend helps me when I am having trouble with something."; $\alpha=77$. at Time 1 and $\alpha=.81$ at Time 2). Security was assessed with five items (e.g., "If I have a problem at school or at home, I can talk to my friend about it."; $\alpha=.60$ at Time 1 and $\alpha=.71$ at Time 2). Closeness was measured with five items ("I feel happy when I am with my friend."; $\alpha=.76$ at Time 1 and $\alpha=.76$ at Time 2). Children rated all items from 1 (not true) to 5 (really true).

We note that some subscales showed somewhat low reliabilities, which are likely due to the small number of items comprising the scales. This problem is alleviated by introducing latent variables with the subscales as indicators.

\section{Strategy of Analyses}

To test Hypothesis 1, binomial logistic regression analyses were performed for reports of interparental conflict by the adolescents and by the parents, respectively. The likelihood of belonging to the friendship instability group was first predicted by early adolescents' perception of interparental conflict at Time 1 (mean score of the three subscales from the CPIC) and then by the parents' perception of negative conflict resolution styles at Time 1 (mean score across four indicators of mothers' and fathers' conflict engagement and withdrawal). In a second analysis, the mediators assessed at Time 2 (adaptive emotion regulation and attachment security) were added as predictors.
To assess the mediation mechanism between perceived interparental conflict and adolescent friendship quality (Hypotheses 2-4), we used the structural equation modeling (SEM) framework and AMOS. Figure 1 shows the mediation model we tested. It implies that perceived interparental conflict measured at Time 1 has an effect on friendship quality at Time 2 directly and indirectly through the consecutive mediators attachment security and adaptive emotion regulation, both measured at Time 2 . In order to control for potential autoregressive processes, friendship quality measured at Time 1 was included as a predictor. All constructs were modelled as latent variables with perceived interparental conflict specified as second-order latent factor. For emotion regulation, the measurement errors of distraction and mood enhancement were allowed to co-vary. Also, covariances between the error terms of the indicators measuring the same aspect of friendship quality at Time 1 and 2 were included (covariances not shown in Fig. 1). To test the mediating (indirect) effects, we used the bootstrap method and 5,000 bootstrap samples. Specific indirect effects were assessed by means of phantom models (Macho and Ledermann 2011).

\section{Results}

Table 1 contains the means, standard deviations, and intercorrelations of all indicators in the study. Low to moderate correlations were found among the proposed indicators (manifest variables).

\section{Predicting Friendship Instability}

First, we tested whether perceived interparental conflict undermines the stability of adolescents' relationships. Therefore, we regressed adolescents friendship stability on perceived interparental conflict at Time 1. The analysis including the adolescents' perception of interparental conflict revealed a significant effect $(b=1.02, p=.008)$. In accordance with Hypothesis 1, perceived interparental conflict increased the risk of experiencing instability in the relationship status with the best friend between Time 1 and Time 2 $(\mathrm{OR}=2.76)$. When emotion regulation and attachment security at Time 2 were added, the effect of perceived interparental conflict was still significant $(b=.90, p=.026$, $\mathrm{OR}=2.46)$; however, neither emotion regulation $(b=.03$, $\mathrm{ns}, \mathrm{OR}=1.03)$ nor attachment security $(b=-.51$, ns, $\mathrm{OR}=.60$ ) had a significant effect on the child's friendship instability. The logistic regression including negative conflict resolution styles, as reported by the parents, showed no significant effect on friendship instability $(b=-.09$, ns, $\mathrm{OR}=.92$ ). This was also true when the analyses were run separately for indicators of maternal and paternal behavior. 


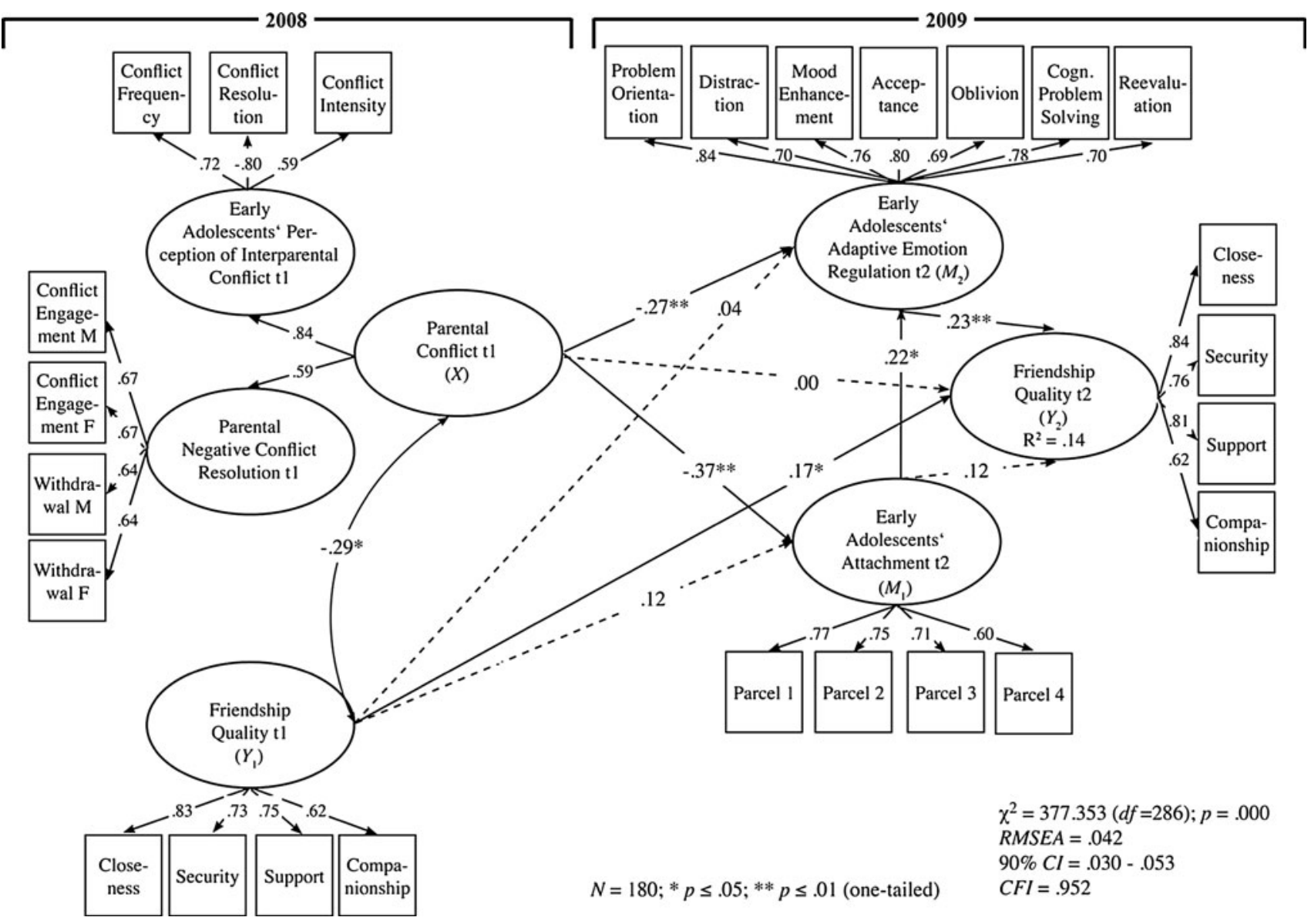

Fig. 1 Structural model of perceived interparental conflict and early adolescents' friendship quality at Time 1 and early adolescents' adaptive emotion regulation, their attachment security to mother and their friendship quality at Time 2 . Standardized path coefficients are presented

Analysis of the Mediation Mechanism

The model to assess the mediating role of attachment security and emotion regulation for the effect from perceived interparental conflict to adolescents' relationships is presented in Fig. 1. Prior to testing this model, we examined the measurement part of the model. Given the importance of measurement invariance of a construct measured at multiple time points, we tested friendship quality for metric invariance. For this purpose, we estimated a model with covariances between the latent variables (rather than the direct paths) and fixed the variances of the latent variables friendship quality (Time 1 and 2), attachment, and emotion regulation to 1 (Kline 2011). This model showed a good fit $\left(\chi^{2}=370.084, d f=283\right.$; RMSEA $=.041 ;$ CFI $=.954)$. In this simpler model, the correlation between perceived interparental conflict and adolescents friendship was -.19 and statistically significant ( $p=.035$, one-tailed). Next, we tested for measurement invariance across adolescents' gender beginning with configural (form) invariance (i.e., both the latent factors and indicators are the same for males and females, but model parameters may differ for males and females). Using multiple group analysis techniques, the fit of the multigroup model was mixed $\left(\chi^{2}=811.977, \quad d f=579\right.$; RMSEA $=.048$, CFI $=.881$ ). Nevertheless, we tested for metric invariance (i.e., invariance of factor loadings for males and females). The likelihood ratio difference test was significant $\left(\Delta \chi^{2}=27.612, \Delta d f=16, p=.035\right)$ indicating that factor loadings were not invariant for male and female adolescents. Therefore, we used single-group techniques to test our mediation hypothesis and the aforementioned good-fitting model that implies invariant factor loadings for the overtime factor adolescents' friendship.

The hypothesized model implying that perceived interparental conflict measured at Time 1 affects friendship quality of the child at Time 2 through the consecutive mediators attachment security at Time 2 and emotion regulation at Time 2 provided a good fit $\left(\chi^{2}=377.353\right.$, $d f=286$; RMSEA $=.042$; CFI $=.952$ ). Figure 1 shows the model with standardized parameter estimates obtained by the maximum likelihood estimation method. Unstandardized estimates of the structural part of the model are given in Table 2. We found that perceived interparental 
Table 1 Intercorrelations and means (with SD) for indicator variables

\begin{tabular}{|c|c|c|c|c|c|c|c|c|c|c|c|c|}
\hline & 1 & 2 & 3 & 4 & 5 & 6 & 7 & 8 & 9 & 10 & 11 & 12 \\
\hline 1. Conflict frequency $\mathrm{t} 1$ & - & & & & & & & & & & & \\
\hline 2. Conflict resolution $\mathrm{t} 1$ & -.57 & - & & & & & & & & & & \\
\hline 3. Conflict intensity t1 & .42 & -.49 & - & & & & & & & & & \\
\hline 4. Mother's withdrawal ${ }^{\mathrm{a}} \mathrm{t} 1$ & .23 & -.28 & .16 & - & & & & & & & & \\
\hline 5. Father's withdrawal ${ }^{\mathrm{a}} \mathrm{t} 1$ & .26 & -.27 & .16 & .42 & - & & & & & & & \\
\hline 6. Mother's conflict engagement ${ }^{\mathrm{a}} \mathrm{t} 1$ & .31 & -.25 & .15 & .41 & .41 & - & & & & & & \\
\hline 7. Father's conflict engagement ${ }^{\mathrm{a}} \mathrm{t} 1$ & .31 & -.16 & .17 & .42 & .46 & .45 & - & & & & & \\
\hline 8. Problem orientation $\mathrm{t} 1$ & -.16 & .17 & -.10 & -.20 & -.12 & -.24 & -.12 & - & & & & \\
\hline 9. Distraction $\mathrm{t} 2$ & -.15 & .16 & -.08 & -.07 & -.15 & -.23 & -.10 & .56 & - & & & \\
\hline 10. Mood enhancement t2 & -.12 & .19 & -.05 & -.10 & -.07 & -.24 & -.05 & .63 & .70 & - & & \\
\hline 11. Acceptance $\mathrm{t} 2$ & -.10 & .26 & -.13 & -.04 & -.07 & -.09 & .04 & .66 & .60 & .59 & - & \\
\hline 12. Oblivion $\mathrm{t} 2$ & -.17 & .20 & -.10 & -.21 & -.08 & -.10 & -.04 & .55 & .51 & .58 & .56 & - \\
\hline 13. Cog. problem solving t 2 & -.24 & .21 & -.22 & -.15 & -.14 & -.16 & -.02 & .71 & .51 & .56 & .62 & .44 \\
\hline 14. Reevaluation $\mathrm{t} 2$ & -.16 & .20 & -.17 & -.11 & -.05 & -.17 & .00 & .57 & .48 & .54 & .55 & .55 \\
\hline 15. Attachment security parcel $1 \mathrm{t} 2$ & -.11 & .10 & -.09 & .01 & -.14 & -.19 & .00 & .19 & .10 & .15 & .22 & .10 \\
\hline 16. Attachment security parcel $2 \mathrm{t} 2$ & -.20 & .19 & -.12 & -.09 & -.12 & -.18 & -.05 & .22 & .12 & .17 & .26 & .11 \\
\hline 17. Attachment security parcel $3 \mathrm{t} 2$ & -.29 & .24 & -.13 & -.02 & -.17 & -.19 & -.05 & .23 & .23 & .21 & .17 & .07 \\
\hline 18. Attachment security parcel $4 \mathrm{t} 2$ & -.31 & .23 & -.27 & -.10 & -.13 & -.24 & -.11 & .14 & .12 & .15 & .16 & .11 \\
\hline 19. Closeness t1 & -.13 & .22 & -.11 & -.08 & -.02 & -.15 & .00 & .09 & .21 & .20 & .05 & .17 \\
\hline 20. Security t1 & -.11 & .31 & -.20 & .01 & -.06 & -.12 & -.04 & .13 & .11 & .15 & .13 & .09 \\
\hline 21. Support t1 & -.02 & .12 & -.01 & -.09 & -.01 & -.20 & -.02 & .09 & .10 & .13 & .02 & .09 \\
\hline 22. Companionship $\mathrm{t} 1$ & -.14 & .23 & -.13 & -.02 & .01 & -.09 & -.02 & .04 & .15 & .19 & .06 & .17 \\
\hline 23. Closeness $\mathrm{t} 2$ & -.10 & .12 & -.14 & -.11 & -.11 & -.15 & -.02 & .23 & .32 & .28 & .24 & .23 \\
\hline 24. Security t2 & -.03 & .05 & -.13 & -.03 & -.02 & -.05 & .09 & .10 & .10 & .04 & .14 & .08 \\
\hline 25. Support t2 & -.04 & .01 & -.09 & -.05 & -.11 & -.13 & -.07 & .11 & .20 & .15 & .14 & .18 \\
\hline 26. Companionship $\mathrm{t} 2$ & -.07 & .15 & -.26 & -.02 & -.07 & -.08 & -.08 & .25 & .23 & .23 & .27 & .25 \\
\hline M & 1.62 & 4.46 & 1.46 & 1.96 & 2.26 & 2.08 & 1.84 & 3.70 & 3.85 & 3.65 & 3.60 & 3.51 \\
\hline SD & 0.53 & 0.64 & 0.56 & 0.72 & 0.83 & 0.74 & 0.69 & 0.94 & 0.96 & 1.04 & 0.91 & 1.03 \\
\hline & 13 & 14 & 15 & 16 & 17 & 10 & 19 & 21 & 22 & 23 & 5 & 26 \\
\hline
\end{tabular}

1. Conflict frequency $\mathrm{t} 1$

2. Conflict resolution $t 1$

3. Conflict intensity $\mathrm{t} 1$

4. Mother's withdrawal ${ }^{\mathrm{a}} \mathrm{t} 1$

5. Father's withdrawal ${ }^{\mathrm{a}} \mathrm{t} 1$

6. Mother's conflict engagement ${ }^{\mathrm{a}} \mathrm{t} 1$

7. Father's conflict engagement ${ }^{\mathrm{a}} \mathrm{t} 1$

8. Problem orientation $\mathrm{t} 1$

9. Distraction $\mathrm{t} 2$

10. Mood enhancement $\mathrm{t} 2$

11. Acceptance $\mathrm{t} 2$

12. Oblivion $\mathrm{t} 2$

13. Cog. problem solving $\mathrm{t} 2$

14. Reevaluation $\mathrm{t} 2$

15. Attachment security parcel 1 t2

16. Attachment security parcel 2 t2

17. Attachment security parcel $3 \mathrm{t} 2$

18. Attachment security parcel 4 t2

19. Closeness t1

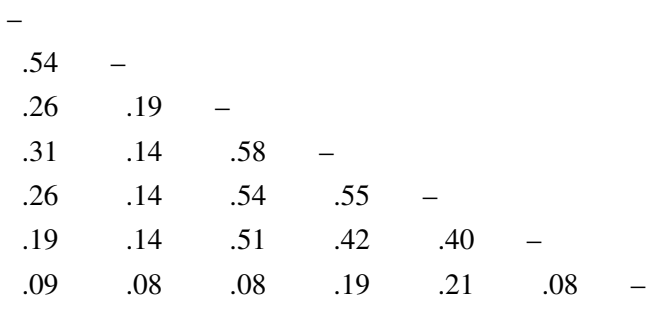


Table 1 continued

\begin{tabular}{|c|c|c|c|c|c|c|c|c|c|c|c|c|c|c|}
\hline & 13 & 14 & 15 & 16 & 17 & 18 & 19 & 20 & 21 & 22 & 23 & 24 & 25 & 26 \\
\hline 20. Security t1 & .14 & .13 & .06 & .17 & .13 & .03 & .59 & - & & & & & & \\
\hline 21. Support t1 & .08 & .09 & .06 & .16 & .18 & .04 & .67 & .51 & - & & & & & \\
\hline 22. Companionship t1 & .13 & .12 & .11 & .12 & .18 & .11 & .50 & .41 & .40 & - & & & & \\
\hline 23. Closeness t2 & .25 & .20 & .24 & .14 & .14 & .19 & .32 & .26 & .11 & .14 & - & & & \\
\hline 24. Security t2 & .16 & .11 & .08 & .08 & .05 & .04 & .11 & .17 & .03 & .08 & .65 & - & & \\
\hline 25. Support t2 & .11 & .09 & .21 & .18 & .12 & .15 & .23 & .14 & .17 & .08 & .67 & .65 & - & \\
\hline 26. Companionship t2 & .28 & .28 & .05 & .07 & .05 & .10 & .03 & .13 & .02 & .28 & .48 & .55 & .51 & - \\
\hline M & 3.41 & 2.93 & 3.54 & 3.50 & 3.70 & 3.78 & 4.41 & 4.46 & 4.18 & 4.07 & 4.50 & 4.52 & 4.38 & 4.14 \\
\hline SD & 1.05 & 0.99 & 0.59 & 0.57 & 0.50 & 0.50 & 0.62 & 0.56 & 0.79 & 0.70 & 0.54 & 0.56 & 0.68 & 0.69 \\
\hline
\end{tabular}

Ns range from 151 to 181

a Mothers' and fathers' report; if not indicated adolescents' report

Table 2 Unstandardized effect estimates among the latent variables

\begin{tabular}{|c|c|c|c|}
\hline Effect & Estimate & SE & $p$ \\
\hline \multicolumn{4}{|l|}{ Direct effects } \\
\hline$X \rightarrow M_{1}$ & -0.350 & 0.123 & .004 \\
\hline$X \rightarrow M_{2}$ & -0.655 & 0.303 & .031 \\
\hline$X \rightarrow Y_{t 2}$ & -0.004 & 0.161 & .979 \\
\hline$M_{1} \rightarrow M_{2}$ & 0.577 & 0.261 & .027 \\
\hline$M_{1} \rightarrow Y_{t 2}$ & 0.162 & 0.141 & .250 \\
\hline$M_{2} \rightarrow Y_{t 2}$ & 0.126 & 0.050 & .013 \\
\hline$Y_{t 1} \rightarrow M_{1}$ & 0.079 & 0.065 & .223 \\
\hline$Y_{t 1} \rightarrow M_{2}$ & 0.074 & 0.154 & 633 \\
\hline$Y_{t 1} \rightarrow Y_{t 2}$ & 0.159 & 0.085 & .061 \\
\hline & Estimate & \multicolumn{2}{|c|}{$95 \%$ Bootstrap C } \\
\hline \multicolumn{4}{|l|}{ Simple indirect effect } \\
\hline$X \rightarrow M_{2} \rightarrow Y_{t 2}$ & -0.082 & \multicolumn{2}{|c|}{$-0.311,-0.009$} \\
\hline \multicolumn{4}{|l|}{ Three-path indirect effect } \\
\hline$X \rightarrow M_{1} \rightarrow M_{2} \rightarrow Y_{t 2}$ & -0.025 & \multicolumn{2}{|c|}{$-0.099,-0.004$} \\
\hline \multicolumn{4}{|l|}{ Total indirect effect } \\
\hline$X \rightarrow Y_{t 2}$ & -0.165 & \multicolumn{2}{|c|}{$-0.468,-0.038$} \\
\hline \multicolumn{4}{|l|}{ Total effect } \\
\hline$X \rightarrow Y_{t 2}$ & -0.169 & \multicolumn{2}{|c|}{$-0.551,0.129$} \\
\hline
\end{tabular}

$X$ perceived interparental conflict at $\mathrm{t} 1, Y$ friendship quality at $\mathrm{t} 1$ and $\mathrm{t} 2, M_{1}$ attachment security at $\mathrm{t} 2, M_{2}$ adaptive emotion regulation at $\mathrm{t} 2$ $S E$ standard error, $C I$ confidence interval

conflict was associated negatively with both attachment security and emotion regulation. The associations were statistically significant, which means that the higher the level of perceived interparental conflict, the lower attachment security and emotion regulation in adolescents is 12 months later. Moreover, attachment security was linked positively and significantly to emotion regulation, which indicates that the higher the attachment security, the better the regulation of emotions is. Finally, emotion regulation was related positively and significantly with friendship quality at Time 2 , suggesting that the better the regulation of emotions, the higher the quality of the adolescents' friendships is. All other direct effects were statistically insignificant.

The significant direct effects make up one simple indirect effect consisting of two direct effects $\left(X \rightarrow M_{2} \rightarrow Y\right)$, one three-path indirect effect involving three direct effects $\left(X \rightarrow M_{1} \rightarrow M_{2} \rightarrow Y\right.$ ) sone total indirect effect (i.e., the sum of all indirect effects) and one total effect (i.e., the sum of the total indirect effect and the direct effect $X \rightarrow Y$ ). The point and bootstrap interval estimates of these effects are presented in Table 2. The simple indirect effect, which connects perceived interparental conflict with friendship quality through emotion regulation, was negative and statistically significant (the bootstrap confidence limit excludes 0 ), which supports Hypothesis 2. Likewise, the three-path indirect effect, which links perceived interparental conflict with friendship quality through the consecutive mediators attachment security and emotion regulation, was negative and significant (H4). In addition, both the total indirect effect and the total effect were negative with the total indirect effect being significant, which provides further evidence for the mediation hypothesis. We note that the direct effect between perceived interparental conflict and friendship quality was positive but not significant. This suggests that the effect from perceived interparental conflict on adolescents' friendship quality was mediated completely through attachment security and emotion regulation.

\section{Discussion}

The current study aimed to investigate the effect of interparental conflict on the stability and quality of early adolescents' relationships with their best same-sex friends. By demonstrating which processes explain the adverse effects of interparental conflict, it contributes to the ongoing 
debate on important third variables that transmit the effect from interparental conflict to adolescents' friendships. We relied on two theoretical approaches: the emotional security hypothesis, according to which interparental conflict lowers the ability to regulate emotions adaptively (Davies and Cummings 1994), and attachment theory, which suggests that interparental conflict undermines the secure attachment between the child and his or her parents (Bowlby 1969). Both emotion regulation and attachment security are known to be related to peer relationships and friendships (e.g., Eisenberg et al. 2004; Schneider et al. 2001). However, no study so far has investigated the mediating role of emotion regulation and attachment security in a single model with interparental conflict and friendship quality as the independent and dependent variables, respectively. The longitudinal finding revealed that early adolescents who perceived more interparental conflict were more likely to report instability in the relationship with their best friend in the following 12 months. In addition, perceived interparental conflict was negatively related to friendship quality 12 months later via the ability to regulate emotions and attachment security and emotion regulation that acted as consecutive mediators.

Our first hypothesis (that interparental conflict is related to instability in early adolescents' friendship status) was confirmed. Early adolescents who perceived more frequent and intense conflicts between parents were twice as likely to see their best friend at Time 1 become their former best friend within a year. This is, as far as we know, the first study that provides evidence for this effect. Whether interparental conflict increases the risk of losing a friend or of just changing the friendship status (or both) remains an open question, as the groups exhibiting friendship instability were too small to be analyzed separately. So does the mechanism whereby interparental conflict affects friendship stability: emotion regulation and attachment security did not mediate this association. The association between parents' perspectives on their conflict resolution styles and the child's friendship instability was not significant. It may be that the conflict resolution styles of parents do not bear on the stability of adolescents' friendships.

The structural equation model corroborated that interparental conflict exerts its influence indirectly through early adolescents' less adaptive emotion regulation and a less secure attachment to the mother (via emotion regulation). On the basis of the emotional security hypothesis (Davies and Cummings 1994) and previous findings on the mediating role of emotion regulation in the association between interparental conflict and children's psychosocial adjustment (e.g., Siffert and Schwarz 2011a), we expected that emotion regulation constitutes an indirect link between interparental conflict and change in friendship quality. Our results supported this hypothesis (H2). As far as we know, this is the first longitudinal study to provide evidence of this process. Moreover, the results broaden the perspective on the phenomenon by showing that interparental conflict is related not only to regulation of emotions that were directly induced by interparental conflict (as shown by Buehler et al. 2007; Harold et al. 2004), but also to adolescents' generalized emotion regulation ability; thus, the results support the hypothesis that experiencing interparental conflict undermines children's ability to cope with negative emotions in diverse situations (Davies and Cummings 1994). Additionally, the results corroborate Nancy Eisenberg's notion (e.g., Eisenberg et al. 2004) that emotion regulation abilities are important for children's social competence and social success; indeed, the current study shows that the same applies to early adolescents and their relationship with their best friend.

We failed to show an indirect effect of interparental conflict on friendship quality via secure attachment to mother (H3); specifically, attachment security was found not to be directly linked to change in friendship quality. This result is not consistent with other studies, which have shown associations between attachment security and friendship quality (see the meta-analysis of Schneider et al. 2001). This inconsistency may relate to the fact that most of these studies differ from our study with respect to the age of the children, and the measures of attachment and friendship quality. Moreover, we detected an indirect path, but it was more complex than postulated in those studies; it was running via attachment security through emotion regulation and, from there, to friendship quality. This result supports our assumption (cf. Contreras and Kerns 2000) that emotion regulation is an indirect link for the association between attachment and friendship quality (H4).

The bootstrapping procedures validated the proposition that both emotion regulation and attachment security were necessary links for the association between interparental conflict and early adolescents' friendship quality at Time 2 after controlling for the initial level of friendship quality. Thus, the study contributes to the ongoing debate about the interconnectedness of personal and familial factors for explaining the effects of interparental conflict on the development of the children and adolescents (Davies et al. 2002; O'Donnell et al. 2010; Stocker et al. 2003) by underlining that multiple pathways explain the adverse effects of interparental conflict.

The early adolescents in the current study reported a high stability in their relationship status with their best same-sex friends across a 1-year period. Fifty-nine percent still had the same best friend at Time 2 and additional $31 \%$ were still friends although no longer best friends. This result is comparable to that of Berndt and Hoyle (1985) and Rubin et al. (2006b) for adolescents of the same age. However, the rank-order stability of friendship quality 
across the 1 -year period was low ( $\beta=.15$ see Fig. 1 ; $r$ 's for the respective indicators are between .17 and .32 , see Table 1), especially when compared to that of Fanti et al. (2009), who reported a rank-order stability of $r=.62$. In that study, the early adolescents rated their feelings for all their friends, hence across a group of different individuals; such a global evaluation might be more stable than the evaluation of a specific relationship. Nevertheless, further research is needed before we can draw firm conclusions about the stability of friendship quality in early adolescence.

Although the longitudinal design of our study is comprehensive, it is not without limitations. The current study was based only on two times of assessment, and the association between attachment security and emotion regulation was tested cross-sectionally (at Time 2); therefore, the causal direction of this association remains unclear. Given the low explained variance of friendship quality at Time 2, further analyses about the development of friendship quality also should include data from the perspective of the friend; however, reports from the best friend of the target adolescents were not available. Further, the results of the study are based on data from higher educated, well-functioning families; whether the results can be generalized to families with a lower socio-economic status and/or with a higher level of interparental conflict remains unclear. Additionally, in the current study, we only included parental reports for perceived interparental conflict but not for other constructs. Maternal report on adolescents' emotion regulation was available, but it was not possible to build a valid and reliable measurement model incorporating these reports, so we decided to refer only to adolescents' perspective on their emotion regulation abilities. The current study is one of the few that has investigated attachment security as a mediator for the association between perceived interparental conflict and early adolescents' development; however, we asked about the relationship with the mothers, but not with the fathers. Other studies emphasize the specific importance of attachment to fathers; for example, Doyle et al. (2009) showed that adolescents' attachment to both mother and father were associated with attachment to the best friend but only attachment to the father contributed uniquely to attachment to the best friend. Furthermore, adolescents' secure attachment to father has been related to less conflict with the best friend (Durchame et al. 2002). Thus, integrating reports on attachment to fathers would provide a more complete picture of the associations between family processes and adolescents' friendships.

The aim of the current study was to broaden our knowledge about the negative effect of interparental conflict on friends' relationships. As far as we know, this study is the first to analyze the association between perceived interparental conflict and early adolescents' relationships with their best friends by using a multi-informant, longitudinal design that integrates the intervening factors emotion regulation and attachment security. The results stress that negative experiences in the family destabilize friendships and decrease the quality of ongoing relationships. Given the beneficial effects of positive relationships with friends in adolescence, the current study provides ideas on how to support these relationships. Specifically, in order to improve the quality of the friendships of early adolescents' in an adverse family situation, their ability to regulate emotions adaptively should be supported. Moreover, parents should maintain a positive, supportive relationship with their adolescent children, as their friendships will benefit (albeit indirectly) from a secure attachment to parents.

Acknowledgments This research was supported by grants (SNF 100013-116500/1; SNF 100014-132278/1) awarded by the Swiss National Science Foundation to the first author. We thank the families who volunteered to participate in the study. We are also grateful to the three anonymous reviewers and the editor Roger J. R. Levesque for helpful suggestions on an earlier version.

\section{References}

Arbuckle, J. L. (2007). Amos 6.0 user's guide. Chicago: SPSS.

Berndt, T. J., \& Hoyle, S. G. (1985). Stability and change in childhood and adolescent friendship. Developmental Psychology, 21, 1007-1015.

Bowlby, J. (1969). Attachment and loss. Attachment (Vol. 1). New York: Basic Books.

Buehler, C., Anthony, C., Krishnakumar, A., Stone, G., Gerard, J., \& Pemberton, S. (1997). Interparental conflict and youth problem behaviors: A meta-analysis. Journal of Child and Family Studies, 6, 233-247.

Buehler, C., Lange, G., \& Franck, K. L. (2007). Adolescents' cognitive and emotional responses to marital hostility. Child Development, 78, 775-789.

Bukowski, W. M., Hoza, B., \& Boivin, M. (1994). Measuring friendship quality during pre- and early-adolescence: The development and psychometric properties of the friendship qualities scale. Journal of Personality Assessment, 49, 71-75.

Collins, W. A., \& Steinberg, L. (2006). Adolescent development in interpersonal context. In N. Eisenberg, W. Damon, \& R. M. Lerner (Eds.), Handbook of child psychology. Hoboken: Wiley.

Contreras, J. M., \& Kerns, K. A. (2000). Emotional regulation processes: Explaining links between parent-child attachment and peer relationships. In K. A. Kerns, J. M. Contreras, \& A. M. Neal-Barnett (Eds.), Family and peers. Linking two social worlds. Westport, CT: Praeger.

Contreras, J. M., Kerns, K. A., Weimer, B. L., Gentzler, A. L., \& Tomich, P. L. (2000). Emotion regulation as a mediator of associations between mother-child attachment and peer relationships in middle childhood. Journal of Family Psychology, $14,111-124$.

Davies, P. T., \& Cummings, E. M. (1994). Marital conflict and child adjustment: An emotional security hypothesis. Psychological Bulletin, 116, 387-411. 
Davies, P. T., Harold, G. T., Goeke-Morey, M. C., \& Cummings, E. M. (2002). Child emotional security and interparental conflict. Monographs of the Society for Research in Child Development, 67(3), 521-535.

Davila, J., Karney, B. R., Hall, T. W., \& Bradbury, T. N. (2003). Depressive symptoms and marital satisfaction: Within-subject associations and the moderating effects of gender and neuroticism. Journal of Family Psychology, 17, 557-570.

Doyle, A. B., \& Markiewicz, D. (2005). Parenting, marital conflict and adjustment from early- to mid-adolescence: Mediated by adolescent attachment style? Journal of Youth and Adolescence, $34,97-110$.

Doyle, A. B., Lawford, H., \& Markiewicz, D. (2009). Attachemnt style with mother, father, best friend, and romantic partner during adolescence. Journal of Research on Adolescence, 19, 690-714.

Durchame, J., Doyle, A. B., \& Markiewicz, D. (2002). Attachment security with mother and father. Associations between adolescents' reports of interpersonal behavior with parents and peers. Journal of Social and Personal Relationships, 19, 203-231.

Eisenberg, N., Fabes, R. A., Guthrie, I. K., \& Reiser, M. (2000). Dispositional emotionality and regulation: Their role in predicting quality of social functioning. Journal of Personality and Social Psychology, 78, 136-157.

Eisenberg, N., Spinrad, T. L., \& Smith, C. L. (2004). Emotion-related regulation: Its conceptualization, relations to social functioning, and socialization. In R. Feldman \& P. Philoppot (Eds.), The regulation of emotion (pp. 277-306). Mahwah, NJ: Erlbaum.

Erel, O., \& Burman, B. (1995). Interrelatedness of marital relations and parent-child relations: A meta-analytic review. Psychological Bulletin, 118, 108-132.

Fanti, K. A., Brookmeyer, K. A., Henrich, C. C., \& Kuperminc, G. P. (2009). Aggressive behavior and quality of friendship. Journal of Early Adolescence, 29, 826-838.

Federal Statistical Office. (2011). Bildungsstand [Educational background]. Retrieved June 14, 2011 from http://www.bfs.admin.ch/ bfs/portal/de/index/themen/15/01/key/blank/01.htm.

Furman, W., \& Buhrmester, D. (1992). Age and sex differences in perceptions of networks of personal relationships. Child Development, 63, 103-115.

Gödde, M., \& Walper, S. (2000). Konfliktstrategien in der Partnerschaft und in der Eltern-Kind-Beziehung [Conflict resolution styles and the parent-child-relationships]. In Paper presented at the 42nd congress of the German Association of Psychology, Jena, Germany.

Gödde, M., \& Walper, S. (2001). Elterliche Konflikte aus der Sicht von Kindern und Jugendlichen: Die deutsche Kurzfassung der children's perception of interparental conflict scale (CPIC) [Children's and adolescents' perception of interparental conflict: The German short version of the children's perception of interparental conflict scale]. Diagnostica, 47, 18-26.

Grob, A., \& Smolenski, C. (2005). Fragebogen zur Erhebung der Emotionsregulation bei Kindern und Jugendlichen (Feel-KJ) [Questionnaire for the assessment of children's and adolescent's emotion regulation]. Bern: Verlag Hans Huber.

Grych, J. H., Seid, M., \& Fincham, F. D. (1992). Assessing marital conflict from the child's perspective: The children's perception of interparental conflict scale. Child Development, 63, 558-572.

Harold, G. T., Shelton, K. H., Goeke-Morey, M. C., \& Cummings, E. M. (2004). Marital conflict, child emotional security about family relationships and child adjustment. Social Development, $13,350-376$.

Harter, S. (1985). Manual for the self-perception profile for children. Denver, CO: University of Denver.

Hartup, W. W. (1996). The company they keep: Friendship and their developmental significance. Child Development, 67, 1-13.
Kerns, K. A., Aspelmeier, J. E., Gentzler, A. L., \& Grabill, C. M. (2001). Parent-child attachment and monitoring in middle childhood. Journal of Family Psychology, 15, 69-81.

Kim, J., \& Cicchetti, D. (2010). Longitudinal pathways linking child maltreatment, emotion regulation, peer relations, and psychopathology. Journal of Child Psychology and Psychiatry, 51, 706-716.

Kinsfogel, K. M., \& Grych, J. H. (2004). Interparental conflict and adolescent dating relationships: Integrating cognitive, emotional, and peer influences. Journal of Family Psychology, 18, 505-515.

Kitzmann, K. M., \& Cohen, R. (2003). Parents' versus children's perception of interparental conflict as predictors of children's friendship quality. Journal of Social and Personal Relationships, 20, 689-700.

Kline, R. B. (2011). Principles and practice of structural equation modeling (3rd ed.). New York: Guilford.

Kurdek, L. A. (1994). Conflict resolution styles in gay, lesbian, heterosexual nonparent, and heterosexual parent couples. Journal of Marriage and the Family, 56, 705-722.

Lansford, J. E., Criss, M. M., Pettit, G. S., Dodge, K. A., \& Bates, J. E. (2003). Friendship quality, peer group affiliation, and peer antisocial behavior as moderators of the link between negative parenting and adolescent externalizing behavior. Journal of Research on Adolescence, 13, 161-184.

Larson, R., \& Richards, M. H. (1991). Daily companionship in late childhood and early adolescence: Changing developmental contexts. Child Development, 62, 284-300.

Lindsey, E. W., Colwell, M. J., Frabutt, J. M., \& MacKinnon-Lewis, C. (2006). Family conflict in divorced and non-divorced families: Potential consequences for boys' friendship status and friendship quality. Journal of Social and Personal Relationships, 23, 45-63.

Lopez, P. N., Salovey, P., Coté, S., \& Beers, M. (2005). Emotion regulation abilities and the quality of social interaction. Emotion, $5,113-118$.

Lucas-Thompson, R., \& Clarke-Stewart, K. A. (2007). Forecasting friendship: How marital quality, maternal mood, and attachment security are linked to children's peer relationships? Applied Developmental Psychology, 28, 499-514.

Macho, S., \& Ledermann, T. (2011). Estimating, testing, and comparing specific effects in structural equation models: The phantom model approach. Psychological Methods, 16, 34-43.

MacKinnon-Lewis, C., \& Lofquist, A. (1996). Antecedents and consequences of boys' depression and aggression: Family and school linkages. Journal of Family Psychology, 10, 490-500.

Mann, B. J., \& Gilliom, L. A. (2002). Emotional security and cognitive appraisals mediate the relationship between parents' marital conflict and adjustment in older adolescents. Journal of Genetic Psychology, 165, 250-271.

Markiewicz, D., Doyle, A. B., \& Brendgen, M. (2001). The quality of adolescents' friendships: Associations with mothers' interpersonal relationships, attachment to parents and friends, and prosocial behaviors. Journal of Adolescence, 24, 429-445.

Noack, P., Krettek, C., \& Walper, S. (2001). Peer relations of adolescents from nuclear and separated families. Journal of Adolescence, 24, 535-548.

O’Donnell, E. H., Moreau, M., Cardemil, E. V., \& Pollastri, A. (2010). Interparental conflict, parenting, and childhood depression in a diverse urban population: The role of general cognitive style. Journal of Youth and Adolescence, 39, 12-22.

Parke, R. D., Kim, M., Flyr, M., McDowell, D. J., Simpkins, S. D., Killian, C. M., et al. (2001). Managing marital conflict: Links with children's peer relationships. In J. H. Grych \& F. D. Fincham (Eds.), Interparental conflict and child development (pp. 291-314). Cambridge: Cambridge University Press. 
Perry-Parrish, C., \& Zeman, J. (2009). Relations among sadness regulation, peer acceptance, and social functioning in early adolescence: The role of gender. Social Development, 20, $135-153$.

Rubin, K. H., Dwyer, K. M., Booth-LaForce, C., Kim, A. H., Burgess, K. B., \& Rose-Krasnor, L. (2004). Attachment, friendship, and psychosocial functioning in early adolescence. Journal of Early Adolescence, 24, 326-356.

Rubin, K. H., Bukowski, W. M., \& Parker, J. G. (2006a). Peer interactions, relationships, and groups. In N. Eisenberg, W. Damon, \& R. M. Lerner (Eds.), Handbook of child psychology. Hoboken, NJ: Wiley.

Rubin, K. H., Wojslawowicz, J. C., Rose-Krasnor, L., Booth-LaForce, C., \& Burgess, K. B. (2006b). The best friendships of shy/ withdrawn children: Prevalence, stability, and relationship quality. Journal of Abnormal Child Psychology, 34, 143-157.

Schneider, B. H., Atkinson, L., \& Tardif, C. (2001). Child-parent attachment and children's peer relations: A quantitative review. Developmental Psychology, 37, 86-100.

Schulz, M. S., Waldinger, R. J., Hauser, S. T., \& Allen, J. P. (2005). Adolescents' behavior in the presence of interparental hostility: Developmental and emotion regulatory influences. Development and Psychopathology, 17, 489-507.

Selfhout, M. H. W., Branje, S. J. T., \& Meeus, W. H. J. (2008). The development of delinquency and perceived friendship quality in adolescent best friendship dyads. Journal of Abnormal Child Psychology, 36, 471-485.

Siffert, A., \& Schwarz, B. (2011a). Parental conflict resolution styles and early adolescent adjustment: Children's appraisals and emotion regulation as mediators. Journal of Genetic Psychology, $171,21-39$.

Siffert, A., \& Schwarz, B. (2011b). Spouses' demand and withdrawal during marital conflict and their well-being. Journal of Social and Personal Relationships, 28, 262-277.

Siffert, A., Schwarz B., \& Stutz, M. (in press). Marital conflict and early adolescents' self-evaluation: The role of parenting quality and early adolescents' appraisals. Journal of Youth and Adolescence. doi:10.1007/s10964-011-9703-1.
Steinberg, S. J., Davila, J., \& Fincham, F. (2006). Adolescent marital expectations and romantic experiences: Associations with perceptions about parental conflict and adolescent attachment security. Journal of Youth and Adolescence, 35, 333-348.

Stocker, C. M., \& Youngblade, L. (1999). Marital conflict and parental hostility: Links with children's sibling and peers relationships. Journal of Family Psychology, 13, 598-609.

Stocker, C. M., Richmond, M. K., Low, S. M., Alexander, E. K., \& Elias, N. M. (2003). Marital conflict and children's adjustment: Parental hostility and children's interpretations as mediators. Social Development, 12, 149-161.

Van de Vijver, F. J. R., \& Leung, K. (1997). Methods and data analysis for cross-cultural research. Thousand Oaks, CA: Sage.

Weimer, B. L., Kerns, K. A., \& Oldenburg, C. M. (2004). Adolescents' interactions with a best friend: Associations with attachment style. Journal of Experimental Child Psychology, 88, $102-120$.

\section{Author Biographies}

Beate Schwarz Department of Applied Psychology, Zurich University of Applied Sciences, Switzerland. Her research interests focus on dysfunctional family processes at the transition into puberty, the role of peers in adolescent development, and cross-cultural psychology.

Melanie Stutz Department of Psychology, University of Basel, Switzerland. Her research interests are socialisation and development of adolescents in the contexts of family and school.

Thomas Ledermann Department of Psychology, University of Basel, Switzerland. His research interests are dyadic data analyses, analyses of mediational and moderational processes, and relationship functioning. 